\title{
Locking Intramedullary Nails Versus Locking Plates in the Treatment of 2-part and 3-part Proximal Humeral Surgical Neck Fractures in Elderly Patients: A Prospective Cohort Study
}

\section{Rui Geng}

Southeast University Zhongda Hospital

Hao Wu

Southeast University Zhongda Hospital

Ke Ren

Southeast University Zhongda Hospital

\section{Qing Chang}

Southeast University Zhongda Hospital

\section{Yalikun Yusufu}

Southeast University Zhongda Hospital

Jihao Xu

Southeast University Zhongda Hospital

Jun Lu ( $\square$ feonixlu1976@163.com )

Southeast University Zhongda Hospital https://orcid.org/0000-0001-5928-8617

Research article

Keywords: proximal humeral fracture, locking intramedullary nail, locking plate, internal fixation, elderly patients

Posted Date: May 27th, 2020

DOI: https://doi.org/10.21203/rs.3.rs-29763/v1

License: (c) (1) This work is licensed under a Creative Commons Attribution 4.0 International License. Read Full License 


\section{Abstract}

Background: Locking intramedullary nails and locking plates are most widely used in the treatment of 2part and 3-part proximal humeral surgical neck fractures, however, the clinical outcomes are controversial. This study aimed to compare the clinical outcomes of treatment with these two implants in elderly patients.

Methods: In this prospective cohort study with a 24-month follow-up period, from June 2014 to November 2016, a total of 53 elderly patients with 2-part and 3-part proximal humeral surgical neck fractures treated with locking intramedullary nails and locking plates were included. We analyzed the intraoperative and radiographic parameters. The American Shoulder and Elbow Surgeons (ASES) score, Constant-Murley score and range of motion (ROM) were used to evaluate shoulder function. We also assessed the visual analog scale (VAS) score and complication rate.

Results: For both 2-part and 3-part proximal humeral surgical neck fractures, the nail group showed statistically significant superiority compared with the plate group in terms of the operative duration, incision length, blood loss, hemoglobin loss, neck-shaft angle (NSA) loss, time to bony union and pain. Good to satisfactory clinical outcomes were obtained with both types of implants. Significant differences were not found in the functional results or complication rate between the two groups at different time points during the follow-up period.

Conclusions: Treatment with both locking intramedullary nails and locking plates achieves similar and good to satisfactory clinical outcomes in elderly patients. We favor locking intramedullary nails, especially in the treatment of 2-part proximal humeral surgical neck fractures.

Trial registration: Medical Ethics Committee for Clinical Research of Zhongda hospital, ZDYJLY (2014) new No. 9. Registered 05 March 2014囚http://www.njzdyy.com

\section{Background}

Proximal humeral fractures are one of the most common fractures of the upper extremity, accounting for approximately $5 \%$ of adult fractures [1]. The incidence of these fractures is increasing, as predicted by Palvanen et al., similar to the incidence of other osteoporosis-related fractures, as a result of the aging population [2]. Satisfactory outcomes can be achieved in patients with good compliance and nondisplaced or minimally displaced fractures through conservative treatment $[3,4]$. However, patients with seriously displaced fractures always require open reduction and internal fixation, especially elderly patients with insufficient bone quality who require a better quality of life [5-7]. Locking intramedullary nails and locking plates are commonly used for the treatment of proximal humeral fractures. Several studies have compared the clinical efficacy of these two implants; however, the results are controversial $[3,8-11]$. 
Locking plates are most commonly used as a standard treatment [8], but the incidence of complications is high [10-12]. Treatment with locking intramedullary nails is more consistent with the principle of minimally invasive surgery $[13,14]$; however, this approach also has several disadvantages, such as the potential for screw displacement and iatrogenic rotator cuff tears $[15,16]$. The improved $3^{\text {rd }}$ generation locking intramedullary nails show better biomechanical advantages and a significantly reduced risk of rotator cuff tear because the nail entry point is in the muscle portion of the supraspinatus [17-19].

According to our working experience, clinical outcomes of using intramedullary nails seemed to be better than using locking plates. Thus, we hypothesized that, with proper surgical techniques, better clinical outcomes could be obtained with locking intramedullary nails in the treatment of 2-part and 3-part proximal humeral surgical neck fractures in elderly patients. The purpose of our study was to further verify which is more suitable in elderly patients.

\section{Methods}

\section{Study design}

The present study was a hospital-based, prospective cohort trial and was approved by the Medical Ethics Committee for Clinical Research of Zhongda hospital.

Inclusion criteria: (1) age $\geq 60$ years; (2) 2-part or 3-part proximal humeral surgical neck fracture, according to the Neer system [20]; (3) fresh fracture $\leq 3$ weeks old; and (4) systematic functional rehabilitation exercises performed after surgery.

Exclusion criteria: (1) pathological fracture; (2) humeral anatomical neck fracture; (3) concomitant humeral head fracture; (4) isolated tuberosity fracture; (5) fracture dislocation; (6) open fracture; (7) multiple fractures of the ipsilateral upper extremity; (8) previous or active infection in the shoulder; (9) frozen shoulder, irreparable rotator cuff tear, or plexus or nerve injury; (10) surgery history in ipsilateral shoulder; and (11) loss to follow-up.

\section{Participants}

From June 2014 to November 2016, 216 patients with a proximal humeral fracture were treated with surgery in our hospital, and 63 patients who were willing to participate and met the inclusion and exclusion criteria were divided into the nail group $\left(\operatorname{TriGen}^{\circledR}\right.$, Smith \& Nephew, London, UK) and the plate group (PHILOS ${ }^{\circledR}$, DePuySynthes, Oberdorf, Switzerland) at the discretion of the surgeon and finally of the patient.

Four patients were lost to follow-up at 12 months postoperatively. At 24 months postoperatively, 4 patients were lost to follow-up, and 2 patients died of a cause unrelated to the surgery. The flowchart is shown in Fig. 1. 


\section{Preoperative evaluation}

We obtained a detailed medical history from every patient. All patients underwent an X-ray examination including an anteroposterior view of the shoulder and a lateral view of the scapular plane, as well as CT for $3 \mathrm{D}$ reconstruction to evaluate the fracture according to the Neer classification system.

\section{Interventions and surgical procedures}

All surgical procedures were performed by senior trauma surgeons with more than 15 years of clinical experience. All patients underwent general anesthesia combined with an interscalene brachial plexus block in the beach chair position. All patients received prophylactic intravenous antibiotics within 30 minutes before the surgery.

\section{Nail group}

We used a syringe needle to confirm the entry point preliminarily under C-arm guidance, and an approximately $4.5-\mathrm{cm}$-long incision was made parallel to Langer's line, lateral to the lower acromion. The deltoid was split between the anterior and middle thirds. We fixed and stretched the deltoid muscles to protect the axillary nerve. If necessary, the "joystick" technique [21] and Kirschner wires could be used to fix the fracture temporarily. Care was taken not to block the path of the nail. A 1-cm-long incision was made in the supraspinatus muscle close to the tendon in line with its muscle fiber orientation. The incision was optimized according to the position of the rotator cuff tear. Under radioscopic imaging, the entry point was located posterolateral to the long head of the biceps tendon in the sulcus between the greater tuberosity and the humeral head margin. The guidewire was introduced after the medullary canal was opened with an awl, and after the fracture was fully reduced, a medullary canal was reamed. The nail was inserted into the medullary cavity along with the guidewire until the nail was placed $4 \mathrm{~mm}$ below the cartilage. Then, at least 3 proximal locking screws and 2 distal locking screws were inserted. Additional tension band sutures were tied around the proximal screw heads to fix the rotator cuff if a comminuted tuberosity was observed, based on the so-called "rope-over-bitt" principle [22]. Finally, an end cap was screwed on, fracture reduction and accurate screw positioning were examined by radioscopic imaging, and a drainage tube was placed before wound closure.

\section{Plate group}

The fracture was exposed via the standard deltopectoral approach. A small bundle of deltoid muscles was first split and stretched to the internal side to wrap and protect the cephalic vein. The hematoma and embedded soft tissue were removed before fracture reduction. Kirschner wires were used to fix the fragments temporarily. Then, a locking plate was positioned on the proximal part of the humerus along the lateral side to the bicipital groove. To avoid subacromial impingement, the plate was placed 
approximately $5 \mathrm{~mm}$ inferior to the tip of the greater tuberosity and $4 \mathrm{~mm}$ lateral to the bicipital groove. Next, a cortical screw was used for distal fixation, and the plate position was examined by radioscopic imaging. A minimum of 5 proximal locking screws and 3 distal locking screws were inserted. Here, a calcar screw could be used to provide medial column support. Radioscopic imaging was used to evaluate fracture reduction and implant position. Finally, the rotator cuff tear was carefully repaired with nonabsorbable tension band sutures through the proximal plate holes, and a drainage tube was placed before wound closure.

\section{Postoperative procedures}

Antibiotics were used continuously for 24 hours after surgery. Postoperative analgesia consisted of Celebrex at $400 \mathrm{mg}$ the first time, followed by $200 \mathrm{mg}$ twice daily for a minimum of 5 days. Narcotic analgesics could be used if necessary. The drainage tube was removed after 48 hours or if the drainage fluid volume was less than $50 \mathrm{ml}$ within 24 hours after surgery.

\section{Postoperative rehabilitation}

Slings were used for 4 weeks. On the operative day and the first postoperative day, active exercises of the fingers, wrist and elbow were performed. Passive forward elevation and abduction were performed on the second postoperative day, and passive external and internal rotation were introduced gradually. Activeassisted exercises were started after 6 weeks, and active antigravity exercises were introduced when callus formation was observed on radioscopic imaging. Improved muscle-strengthening and activeresistance exercises were started after 12 weeks. Detailed rehabilitation protocol is given in a table [see Additional file 1].

\section{Demographic characteristics}

We recorded the sex, age, injured shoulder, Neer classification, coronal deviation, interval between injury and surgery, number of medial cortical comminutions and follow-up period.

\section{Intraoperative parameters}

The intraoperative parameters included the operative duration, incision length, blood loss, and hemoglobin loss at 24 hours postoperatively.

\section{Postoperative radiographic parameters}


Radiographs were obtained for the first time after the drainage tube was removed and at 1.5, 3, 6, 12 and 24 months postoperatively. The parameters included the neck-shaft angle (NSA) immediately postoperatively and at 24 months postoperatively, NSA loss, and time to callus formation and bony union. Bony union was defined upon the formation of callus bridging the main fracture fragments in $80 \%$ of the cortex.

\section{Functional outcomes}

Functional results were evaluated using the American Shoulder and Elbow Surgeons (ASES) score, Constant-Murley score, and visual analog scale (VAS) score at 3, 6, 12 and 24 months postoperatively. In addition, the VAS score was recorded on the first postoperative day. Forward elevation, abduction, and external rotation were measured by a goniometer and are expressed as an angle $\left(^{\circ}\right)$, and internal rotation was measured according to the height of the back touched by the thumb, which was ranked using a continuous number.

Complications included tuberosity resorption, loss of reduction of the greater tuberosity $(\geq 0.5 \mathrm{~cm})$, varusmalunion $\left(\mathrm{NSA} \leq 120^{\circ}\right.$ ), screw penetration, subacromial impingement, humeral head avascular osteonecrosis, refracture, infection, iatrogenic nerve injury, iatrogenic rotator cuff tear and nonunion.

\section{Statistical analysis}

All data were analyzed using SPSS Statistics 20.0 (SPSS, IBM, New York, USA). Continuous variables are presented as the mean and standard deviation and were analyzed using Student's t-test when normally distributed or the Mann-Whitney U test when non-normally distributed. Categorical variables are presented as absolute numbers and were analyzed using the chi-squared test. In addition, internal rotation and the VAS scores are presented as the median and range and were analyzed using the MannWhitney $U$ test. $P<0.05$ was considered statistically significant.

\section{Results}

\section{Demographic characteristics}

A total of 53 patients were available for final evaluation. The average age was $71.6 \pm 8.0$ years in the nail group and $69.9 \pm 8.5$ years in the plate group. There were 25 patients in the nail group (12 with 2-part fractures and 13 with 3-part fractures) and 28 patients in the plate group (15 with 2-part fractures and 13 with 3-part fractures). Ten patients in the nail group and 12 patients in the plate group had valgus deformity, and 13 patients in both the nail group and the plate group had varus deformity. Medial cortical comminutions were found in 4 patients in the nail group and 6 patients in the plate group. The interval between injury and surgery was $4.6 \pm 1.4$ days in the nail group and $4.7 \pm 1.3$ days in the plate group. The average follow-up period was $26.0 \pm 2.6$ (range, from 24 to 29) months in the nail group compared with 
$27.0 \pm 2.5$ (range, from 24 to 30 ) months in the plate group. Each group had comparable demographic characteristics, and no significant differences were found (Table 1).

Table 1

Demographic Characteristics

\begin{tabular}{|c|c|c|c|c|}
\hline & Nail group & Plate group & $x^{2} / t$ & P-value \\
\hline & $(n=25)$ & $(n=28)$ & & \\
\hline Sex ${ }^{a}$ & & & 0.121 & 0.728 \\
\hline Male & 11 & 11 & & \\
\hline Female & 14 & 17 & & \\
\hline Age $(\text { year })^{b}$ & $71.6 \pm 8.0$ & $69.9 \pm 8.5$ & 0.586 & 0.561 \\
\hline Injured shoulder ${ }^{a}$ & & & 0.191 & 0.662 \\
\hline Left & 14 & 14 & & \\
\hline Right & 11 & 14 & & \\
\hline Neer system ${ }^{\mathrm{a}}$ & & & 0.164 & 0.685 \\
\hline 2-part & 12 & 15 & & \\
\hline 3-part & 13 & 13 & & \\
\hline Coronal deviation $^{a}$ & & & 0.099 & 0.753 \\
\hline Valgus & 10 & 12 & & \\
\hline Varus & 13 & 13 & & \\
\hline Medial cortical comminution ${ }^{a}$ & 4 & 6 & 0.023 & 0.879 \\
\hline $\begin{array}{l}\text { Interval between } \\
\text { injury and surgery (day) }\end{array}$ & $4.6 \pm 1.4$ & $4.7 \pm 1.3$ & -0.306 & 0.761 \\
\hline Follow-up period (month) ${ }^{\mathrm{b}}$ & $26.0 \pm 2.6$ & $27.0 \pm 2.5$ & -1.453 & 0.152 \\
\hline
\end{tabular}

\section{Intraoperative parameters}


For both 2-part and 3-part proximal humeral surgical neck fractures, significant decreases in the operative duration ( $P=0.007$ in 2-part fractures, $P=0.041$ in 3-part fractures), incision length $(P<0.001$ in 2-part fractures, $P<0.001$ in 3-part fractures), blood loss $(P<0.001$ in 2-part fractures, $P<0.001$ in 3-part fractures), and hemoglobin loss at 24 hours postoperatively $(P=0.007$ in 2-part fractures, $P=0.001$ in 3 part fractures) were observed in the nail group compared with the plate group (Table 2 ).

Table 2

Intraoperative parameters

\begin{tabular}{|lllll|}
\hline & Nail group & Plate group & t & P-value \\
\hline 2-part & & & & \\
\hline Operative duration (minute) & $82.5 \pm 14.2$ & $103.7 \pm 22.5$ & -2.977 & 0.007 \\
\hline Incision length (cm) & $6.3 \pm 0.3$ & $15.1 \pm 2.1$ & -16.127 & $<0.001$ \\
\hline Blood loss (mL) & $97.5 \pm 12.9$ & $178.7 \pm 20.3$ & -12.021 & $<0.001$ \\
\hline Hemoglobin loss at 24 h (g/L) & $11.9 \pm 2.7$ & $16.7 \pm 5.4$ & -3.007 & 0.007 \\
\hline 3-part & & & & \\
\hline Operative duration (minute) & $104.6 \pm 13.3$ & $122.7 \pm 26.4$ & -2.203 & 0.041 \\
\hline Incision length (cm) & $7.2 \pm 0.6$ & $15.8 \pm 2.7$ & -11.172 & $<0.001$ \\
\hline Blood loss (mL) & $121.5 \pm 12.8$ & $209.2 \pm 32.8$ & -8.984 & $<0.001$ \\
\hline Hemoglobin loss at 24 $\mathrm{h}(\mathrm{g} / \mathrm{L}$ ) & $13.5 \pm 4.8$ & $19.6 \pm 3.7$ & -3.630 & 0.001 \\
\hline All values are presented as means and standard deviations and analyzed using Student's t-test. \\
\hline
\end{tabular}

\section{Radiographic parameters}

For both 2-part and 3-part proximal humeral surgical neck fractures, there were no significant differences in the NSA immediately postoperatively or at 24 months postoperatively between the two groups.

Significant decreases in NSA loss ( $P=0.029$ in 2-part fractures, $P=0.037$ in 3-part fractures), and time to callus formation ( $P=0.001$ in 2-part fractures, $P=0.007$ in 3-part fractures), and bony union $(P=0.042$ in 2-part fractures, $P=0.039$ in 3-part fractures) were observed in the nail group compared with the plate group (Table 3). Two typical cases are shown in Fig. 2. 
Table 3

Radiographic parameters postoperatively

\begin{tabular}{|lllll|}
\hline & Nail group & Plate group & t & P-value \\
\hline 2-part & & & & \\
\hline Immediate NSA $\left(^{\circ}\right)$ & $137.0 \pm 6.1$ & $136.1 \pm 5.7$ & 0.381 & 0.706 \\
\hline NSA at 24 months $\left(^{\circ}\right)$ & $133.9 \pm 6.6$ & $130.4 \pm 6.4$ & 1.397 & 0.175 \\
\hline NSA loss $\left(^{\circ}\right)$ & $3.1 \pm 1.6$ & $5.7 \pm 4.0$ & -2.365 & 0.029 \\
\hline Callus formation time (week) & $5.3 \pm 0.6$ & $6.3 \pm 0.7$ & -3.925 & 0.001 \\
\hline Bony union time (week) & $11.6 \pm 1.3$ & $13.1 \pm 2.1$ & -2.143 & 0.042 \\
\hline 3-part & & & & \\
\hline Immediate NSA $\left(^{\circ}\right)$ & $134.0 \pm 8.3$ & $136.2 \pm 6.1$ & -0.750 & 0.461 \\
\hline NSA at 24 months $\left(^{\circ}\right)$ & $130.5 \pm 8.4$ & $129.2 \pm 8.5$ & 0.372 & 0.713 \\
\hline NSA loss $\left({ }^{\circ}\right)$ & $3.5 \pm 2.6$ & $6.9 \pm 4.8$ & -2.246 & 0.037 \\
\hline Callus formation time (week) & $5.6 \pm 1.0$ & $6.8 \pm 1.1$ & -2.971 & 0.007 \\
\hline Bony union time (week) & $13.0 \pm 1.6$ & $14.5 \pm 1.9$ & -2.187 & 0.039 \\
\hline All values are presented as means and standard deviations and analyzed using Student's t-test. & & \\
\hline NSA: Neck-shaft angle & & & & \\
\hline
\end{tabular}

\section{Functional scores}

For 2-part proximal humeral surgical neck fractures, there were no significant differences in the ASES or Constant-Murley score between the nail and plate groups after 3, 6, 12, or 24 months (Table 4). Although both the ASES and Constant-Murley scores in the two groups continued to increase during the entire follow-up period, significant differences in the ASES and Constant-Murley score were found only between 3 and 6 months and were not found at 6,12 or 24 months in the nail group. In the plate group, significant differences in the ASES and Constant-Murley scores were found at 3, 6 and 12 months and were not found between 12 and 24 months (Fig. 3). 
Table 4

Clinical outcomes for 2-part proximal humeral surgical neck fractures

\begin{tabular}{|c|c|c|c|c|c|}
\hline & & Nail group & Plate group & $\mathrm{Z} / \mathrm{t}$ & P-value \\
\hline \multirow[t]{4}{*}{ ASES score ${ }^{a}$} & 3 months & $50.3 \pm 13.9$ & $45.4 \pm 12.4$ & 0.973 & 0.340 \\
\hline & 6 months & $66.2 \pm 12.1$ & $62.2 \pm 12.3$ & 0.841 & 0.409 \\
\hline & 12 months & $75.3 \pm 9.6$ & $73.0 \pm 11.5$ & 0.562 & 0.579 \\
\hline & 24 months & $79.1 \pm 8.2$ & $76.9 \pm 9.4$ & 0.642 & 0.527 \\
\hline \multirow[t]{4}{*}{ Constant-Murley score ${ }^{a}$} & 3 months & $53.4 \pm 14.7$ & $47.5 \pm 13.1$ & 1.114 & 0.276 \\
\hline & 6 months & $69.5 \pm 12.5$ & $65.5 \pm 13.0$ & 0.816 & 0.422 \\
\hline & 12 months & $77.5 \pm 9.5$ & $75.2 \pm 11.5$ & 0.557 & 0.582 \\
\hline & 24 months & $80.8 \pm 8.0$ & $79.1 \pm 10.4$ & 0.440 & 0.664 \\
\hline \multirow[t]{4}{*}{ Forward elevation $\left({ }^{\circ}\right)^{a}$} & 3 months & $84.8 \pm 10.4$ & $80.2 \pm 7.9$ & 1.290 & 0.209 \\
\hline & 6 months & $113.3 \pm 12.7$ & $110.8 \pm 10.9$ & 0.539 & 0.595 \\
\hline & 12 months & $137.9 \pm 13.7$ & $137.7 \pm 12.4$ & 0.050 & 0.961 \\
\hline & 24 months & $147.7 \pm 11.9$ & $146.1 \pm 11.3$ & 0.357 & 0.724 \\
\hline \multirow[t]{4}{*}{ Abduction $\left({ }^{\circ}\right)^{a}$} & 3 months & $69.5 \pm 18.5$ & $68.3 \pm 13.3$ & 0.191 & 0.850 \\
\hline & 6 months & $94.3 \pm 14.9$ & $91.1 \pm 15.5$ & 0.542 & 0.592 \\
\hline & 12 months & $118.2 \pm 14.9$ & $120.5 \pm 14.1$ & -0.423 & 0.676 \\
\hline & 24 months & $129.8 \pm 13.5$ & $130.8 \pm 14.5$ & -0.193 & 0.849 \\
\hline \multirow[t]{4}{*}{ External rotation $\left({ }^{\circ}\right)^{a}$} & 3 months & $20.4 \pm 6.2$ & $19.1 \pm 5.7$ & 0.590 & 0.560 \\
\hline & 6 months & $29.4 \pm 8.1$ & $27.3 \pm 7.8$ & 0.697 & 0.493 \\
\hline & 12 months & $39.4 \pm 8.1$ & $36.3 \pm 9.0$ & 0.939 & 0.356 \\
\hline & 24 months & $43.8 \pm 7.4$ & $41.8 \pm 10.0$ & 0.564 & 0.578 \\
\hline \multirow[t]{2}{*}{ Internal rotation ${ }^{b}$} & 3 months & S3 (buttock-S3) & S5 (buttock-S1) & -0.753 & 0.452 \\
\hline & 6 months & L4 (S5-L3) & L5 (S5-L3) & -1.104 & 0.270 \\
\hline
\end{tabular}

${ }^{\text {a }}$ The values are presented as means and standard deviations and analyzed using Student's t-test.

${ }^{\mathrm{b}}$ The values are presented as median with range in parentheses and analyzed using the MannWhitney U test.

ASES: American Shoulder and Elbow Surgeons; VAS: visual analog scale. 


\begin{tabular}{|c|c|c|c|c|c|}
\hline & 12 months & T12 (S3-T11) & L2 (S3-T11) & -1.458 & 0.145 \\
\hline & 24 months & T9 (S1-T7) & T10 (S3-T8) & -1.258 & 0.208 \\
\hline \multirow[t]{5}{*}{ VAS score ${ }^{b}$} & 1 day & $4.5(2-5)$ & $5(4-8)$ & -2.620 & 0.009 \\
\hline & 3 months & $3(1-4)$ & $3(2-4)$ & -1.491 & 0.136 \\
\hline & 6 months & $2(1-3)$ & $2(1-4)$ & -0.772 & 0.440 \\
\hline & 12 months & $1(0-2)$ & $1(1-2)$ & -0.168 & 0.867 \\
\hline & 24 months & $1(0-2)$ & $1(0-2)$ & -0.445 & 0.656 \\
\hline \multicolumn{6}{|c|}{$\begin{array}{l}\text { a'The values are presented as means and standard deviations and analyzed using Student's t-tes } \\
\text { bThe values are presented as median with range in parentheses and analyzed using the Mann- } \\
\text { Whitney U test. }\end{array}$} \\
\hline \multicolumn{6}{|c|}{ ASES: American Shoulder and Elbow Surgeons; VAS: visual analog scale. } \\
\hline
\end{tabular}

The trends in the statistical results for 3-part fractures agreed with those for 2-part fractures. In addition, significant differences in the ASES and Constant-Murley scores were found at 3, 6 and 12 months and were not found between 12 and 24 months in the two groups (Table 5, Fig. 3). 
Table 5

Clinical outcomes for 3-part proximal humeral surgical neck fractures

\begin{tabular}{|c|c|c|c|c|c|}
\hline & & Nail group & Plate group & $\mathrm{Z} / \mathrm{t}$ & P-value \\
\hline \multirow[t]{4}{*}{ ASES scor ${ }^{a}$} & 3 months & $43.8 \pm 11.4$ & $40.3 \pm 9.6$ & 0.858 & 0.399 \\
\hline & 6 months & $57.2 \pm 11.0$ & $55.5 \pm 11.0$ & 0.640 & 0.528 \\
\hline & 12 months & $69.7 \pm 11.6$ & $68.4 \pm 10.1$ & 0.306 & 0.762 \\
\hline & 24 months & $74.0 \pm 11.5$ & $73.2 \pm 10.6$ & 0.178 & 0.860 \\
\hline \multirow[t]{4}{*}{ Constant-Murley score } & 3 months & $45.6 \pm 11.0$ & $41.3 \pm 8.7$ & 1.106 & 0.280 \\
\hline & 6 months & $59.5 \pm 10.7$ & $57.6 \pm 10.6$ & 0.442 & 0.663 \\
\hline & 12 months & $72.1 \pm 11.9$ & $70.9 \pm 9.9$ & 0.268 & 0.791 \\
\hline & 24 months & $75.1 \pm 10.7$ & $74.5 \pm 10.5$ & 0.122 & 0.904 \\
\hline \multirow[t]{4}{*}{ Forward elevation $\left({ }^{\circ}\right)^{a}$} & 3 months & $74.5 \pm 10.2$ & $72.0 \pm 7.4$ & 0.725 & 0.476 \\
\hline & 6 months & $100.6 \pm 11.7$ & $104.4 \pm 13.5$ & -0.760 & 0.454 \\
\hline & 12 months & $126.9 \pm 11.9$ & $125.5 \pm 14.4$ & 0.267 & 0.792 \\
\hline & 24 months & $135.8 \pm 12.8$ & $136.4 \pm 13.5$ & -0.119 & 0.906 \\
\hline \multirow[t]{4}{*}{ Abduction $\left({ }^{\circ}\right)^{a}$} & 3 months & $58.5 \pm 16.1$ & $61.1 \pm 13.3$ & -0.452 & 0.655 \\
\hline & 6 months & $81.6 \pm 18.9$ & $84.1 \pm 14.4$ & -0.374 & 0.712 \\
\hline & 12 months & $107.4 \pm 19.7$ & $112.8 \pm 12.6$ & -0.831 & 0.414 \\
\hline & 24 months & $115.9 \pm 18.7$ & $122.2 \pm 13.0$ & -0.997 & 0.329 \\
\hline \multirow[t]{4}{*}{ External rotation $\left({ }^{\circ}\right)^{a}$} & 3 months & $17.5 \pm 4.5$ & $18.8 \pm 4.6$ & -0.773 & 0.447 \\
\hline & 6 months & $28.1 \pm 7.8$ & $26.3 \pm 6.3$ & 0.641 & 0.528 \\
\hline & 12 months & $33.2 \pm 8.9$ & $33.9 \pm 6.9$ & -0.247 & 0.807 \\
\hline & 24 months & $38.9 \pm 9.2$ & $37.5 \pm 8.2$ & 0.429 & 0.672 \\
\hline \multirow[t]{3}{*}{ Internal rotation ${ }^{b}$} & 3 months & S5 (buttock-S1) & S5 (buttock-S5) & -0.730 & 0.465 \\
\hline & 6 months & S1 (S5-L4) & S1 (S5-L5) & -0.943 & 0.346 \\
\hline & 12 months & L3 (S3-T12) & L4 (S5-L2) & -1.021 & 0.307 \\
\hline
\end{tabular}

${ }^{a}$ The values are presented as means and standard deviations and analyzed using Student's t-test.

${ }^{\mathrm{b}}$ The values are presented as median with range in parentheses and analyzed using the MannWhitney U test. 


\begin{tabular}{|c|c|c|c|c|c|}
\hline & 24 months & T12 (S1-T9) & L1 (S3-T10) & -1.012 & 0.311 \\
\hline \multirow[t]{5}{*}{ VAS score ${ }^{b}$} & 1 day & $5(2-6)$ & $6(4-8)$ & -2.100 & 0.036 \\
\hline & 3 months & $3(1-4)$ & $3(2-5)$ & -1.174 & 0.240 \\
\hline & 6 months & $2(1-3)$ & $2(1-4)$ & -0.810 & 0.418 \\
\hline & 12 months & $1(1-3)$ & $2(1-4)$ & -0.722 & 0.470 \\
\hline & 24 months & $1(0-2)$ & $1(0-3)$ & -1.221 & 0.222 \\
\hline \multicolumn{6}{|c|}{$\begin{array}{l}\text { bThe values are presented as median with range in parentheses and analyzed using the Mann- } \\
\text { Whitney U test. }\end{array}$} \\
\hline
\end{tabular}

\section{Range of motion (ROM)}

For both 2-part and 3-part proximal humeral surgical neck fractures, as determined after 3, 6, 12, and 24 months, the ROM, including active forward elevation, abduction, external rotation, and internal rotation, continued to increase during the entire follow-up period. No significant differences were found between the two groups at the different time points during the follow-up period (Tables 4 and 5, Fig. 3).

\section{VAS score}

For both 2-part and 3-part humeral surgical neck fractures, the median VAS score was significantly lower in the nail group than in the plate group on the first postoperative day $(P=0.009$ in 2-part fractures, $P=$ 0.036 in 3-part fractures). Although the median VAS score was lower in the nail group than in the plate group after 3, 6, 12 and 24 months, there were no significant differences between the two groups (Tables 4 and 5). Here, the VAS score is also presented as the mean and standard deviation to show the decreasing trend in both groups (Fig. 4).

\section{Complications}

A total of 7 complications were recorded, 3 in the nail group $(12.0 \%, 1$ in 2-part fractures and 2 in 3-part fractures) and 4 in the plate group (14.3\%, 1 in 2-part fractures and 3 in 3-part fractures). A significant difference was not found in the incidence of complications between the two groups $(P=1.000)$.

For 2-part proximal humeral surgical neck fractures, wound infection with Staphylococcus epidermidis was found in 1 patient at 3 days postoperatively in the nail group and was cured using intravenous vancomycin and dressing changes. Screw penetration beyond the subchondral bone was found in 1 patient in the plate group, and the penetrated screw was removed at 3 months postoperatively. For 3-part 
fractures, in the nail group, there was 1 case of greater tuberosity resorption. Additionally, an 84-year-old female patient suffered from subacromial impingement in her left shoulder, and the patient refused to undergo implant removal because she said the condition had no serious impact on daily life. In the plate group, there was 1 case of loss of reduction of the greater tuberosity and 1 case of varusmalunion (the NSA was $115^{\circ}$ at 24 months). In addition, 1 patient suffered from humeral head avascular osteonecrosis (Cruess IV [23]) and underwent shoulder hemiarthroplasty at 24 months postoperatively (Table 6).

Table 6

Complications

\begin{tabular}{|c|c|c|c|c|}
\hline & 2-part & & 3-part & \\
\hline & $\begin{array}{l}\text { Nail } \\
\text { group }\end{array}$ & $\begin{array}{l}\text { Plate } \\
\text { group }\end{array}$ & $\begin{array}{l}\text { Nail } \\
\text { group }\end{array}$ & $\begin{array}{l}\text { Plate } \\
\text { group }\end{array}$ \\
\hline & $(n=12)$ & $(n=15)$ & $(n=13)$ & $(n=13)$ \\
\hline Tuberosity resorption & - & - & 1 & - \\
\hline $\begin{array}{l}\text { Loss of reduction of the greater } \\
\text { tuberosity }\end{array}$ & - & - & - & 1 \\
\hline Varus malunion & - & - & - & 1 \\
\hline Screw penetration & - & 1 & - & - \\
\hline Subacromial impingement & - & - & 1 & - \\
\hline Avascular osteonecrosis & - & - & - & 1 \\
\hline Refracture & - & - & - & - \\
\hline Infection & 1 & - & - & - \\
\hline latrogenic nerve injury & - & - & - & - \\
\hline latrogenic rotator cuff tear & - & - & - & - \\
\hline Nonunion & - & - & - & - \\
\hline
\end{tabular}

No cases of refracture, iatrogenic nerve injury, iatrogenic rotator cuff tear, or nonunion were found in any of the patients.

\section{Discussion}

In elderly patients with proximal humeral fractures, conservative treatment may result in severe complications, such as fracture nonunion, malunion, and traumatic arthritis [24]. Indications for surgical treatment include angulation $\geq 45^{\circ}$ between fracture fragments, displacement $\geq 1 \mathrm{~cm}$ of the humeral shaft against the humeral head or displacement $\geq 0.5 \mathrm{~cm}$ of the greater tuberosity [25]. As proximal 
humeral fractures are intracapsular fractures, anatomical reduction must be achieved, while damage to the periosteum and soft tissue should be minimized, and the blood supply to the metaphysis should be protected as much as possible.

Locking plates are most widely used and can achieve good clinical outcomes. In a long-term study of 43 patients reported by Ockert et al., the absolute Constant-Murley score was 75.3; most of the patients showed good to excellent clinical outcomes 10 years after the surgery, with no relevant statistical decline in shoulder function compared with 1 year after surgery [8]. However, locking plates are associated with a greater incidence of complications. Hertel et al. reported that the integrity of the medial column was one of the most relevant predictors of ischemia [26]. Osterhoff et al. proved that the placement of calcar screws in the fixation of proximal humeral fractures could provide inferomedial support to reduce the risk of complications [27]. Cha et al. reported that fixation using a locking plate with an endosteal strut allograft can maintain anatomical reduction in elderly patients with comminuted proximal humeral fractures [28].

Intramedullary nails are effective in stabilizing proximal humeral fractures and conform more to the principle of minimal invasiveness. Unique advantages include a preservation effect on the blood supply around the fracture, central fixation, and advanced biomechanical properties [29, 30] (axial, torsional and bending loads). The early designs of $1^{\text {st }}$ generation (unlocked) and $2^{\text {nd }}$ generation (bent design) intramedullary nails had high rates of reoperations and complications, especially regarding the risk of underlying iatrogenic rotator cuff tear and chronic shoulder pain [31]. In addition, these nails were not recommended for patients with comminuted tuberosity fractures. The newly developed $3^{\text {rd }}$ generation locking intramedullary nails (straight, multilocking, low-profile nails allowing tuberosity-based fixation) overcome these problems [18].

In our study, the operative duration was significantly shorter in the nail group. We have performed this kind of treatment for many years, and the surgeons involved in the surgeries were experienced and skilled, allowing the surgery to be finished in a short time. One study has suggested that the decreased operative duration may be related to the minimally invasive approach [9]. The application of this treatment could shorten the incision length, reduce bleeding, reduce soft tissue stripping, and protect blood vessels around the fracture and thus reduce the time to callus formation and bony union. However, the technique is difficult, and the learning curve is long. Therefore, it is recommended that beginners start with simple 2part proximal humeral surgical neck fractures.

The functional scores and ROM were comparable between the two groups at different time points during the follow-up period in our study. Most researchers have reported good to satisfactory clinical outcomes after surgical treatment using these two implants. Ge et al. performed a prospective study to compare the clinical outcomes of treatment with intramedullary nails, locking plates and conservative treatment for 2-part and 3-part proximal humeral fractures in elderly patients, and the results suggested that similar functional outcomes can be achieved using locking intramedullary nails and locking plates [4]. In a randomized controlled trial, Gracitelli et al. also found that proximal humeral 
surgical neck fracture fixation with these two implants produces similar results [32]. Xiang et al. concluded that 2-part proximal humeral fracture fixation with a locking intramedullary nail achieved superior functional scores and ROM [33]. The mean age of the patients was younger (57.2 \pm 7.4 years), and young patients were also included in their study, which might have led to the divergence. In our study, for 2-part fractures, significant differences in functional scores were found only between 3 and 6 months and were not found at 6,12 or 24 months in the nail group, which suggests that quick recovery could be achieved in patients with simple 2-part proximal humeral surgical neck fractures using locking intramedullary nails.

A significant difference was not found in the total complication rate between the two groups in our study, which is identical to the result of a meta-analysis based on 1384 individuals [34]. In the nail group, postoperative wound infection was found in one patient. Fortunately, it was cured without any serious consequences. The large diameter of the proximal locking screws was not suitable for small fragments of the greater tuberosity, which might result in tuberosity resorption. Regarding subacromial impingement, postoperative radiographs at 6 months suggested that the end cup was slightly higher than the humeral head, which caused the nail to collide with the acromion during abduction of the shoulder joint. This might have been the result of incorrect positioning of the C-arm during surgery. In addition, vertical reduction loss and humeral head subsidence might also result in upward movement of the nail. Furthermore, there were no cases of iatrogenic rotator cuff tear due to the use of $3^{\text {rd }}$ generation intramedullary nails with an improved entry point, which is identical to Boileau's study [18]. In the plate group, a decrease in the screw holding strength decreasing and the loosening of internal fixation might have been the result of the loss of reduction of the greater tuberosity. The force on the screw tip was high, while the so-called "screw-bone interface" was weak, which might explain screw penetration in elderly patients with osteoporosis. We reconstructed the medial column with only one calcar screw but without autologous bone grafting to treat the medial cortical comminution, which might result in varusmalunion and avascular osteonecrosis. Damage to blood vessels and the periosteum caused by a wider approach might also result in avascular osteonecrosis.

Several limitations of this study should be considered. First, the patients were not randomly assigned, and the treatments were decided based on both the patients' choices and surgeons' advice, but the demographic characteristics were comparable. Second, the 24-month follow-up duration might result in an underestimation of the long-term complication rate. Another limitation was the small sample size. Therefore, validation by more multicenter, prospective, randomized controlled studies with larger sample sizes and longer-term follow-up periods is needed to confirm our findings.

\section{Conclusions}

With advanced surgical techniques and scientific postoperative rehabilitation methods, both locking intramedullary nails and locking plates could be used in the treatment of 2-part and 3-part proximal humeral surgical neck fractures in elderly patients with good to satisfactory clinical outcomes. We favor locking intramedullary nails due to the advantages of a reduced operative duration, incision length, blood 
loss, hemoglobin loss, NSA loss, time to bony union and pain, especially in the treatment of 2-part proximal humeral surgical neck fractures.

\section{List Of Abbreviations}

ASES: American Shoulder and Elbow Surgeons; ROM: range of motion; VAS: visual analog scale; NSA: Neck-shaft angle;

\section{Declarations}

\section{Ethics approval and consent to participate}

The present study was approved by the Medical Ethics Committee for Clinical Research of Zhongda hospital (number: ZDYJLY (2014) new No. 9) and was in accordance with the 1964 Helsinki declaration and its later amendments or comparable ethical standards. Written informed consent was obtained from all individuals.

\section{Consent for publication}

Not applicable.

\section{Availability of data and materials}

The datasets used and/or analyzed during the current study are available from the corresponding author on reasonable request.

\section{Competing interests}

The authors declare that they have no competing interests.

\section{Funding}

This study was founded by the National Natural Science Foundation of China (No.81673017).

\section{Authors' contributions}

All authors contributed to the study conception and design. Hao Wu, Yalikun Yusufu and Jihao Xu collected the data. Rui Geng and Qing Chang analyzed and interpreted the data. Rui Geng wrote the first 
draft of the manuscript. Jun Lu and Ke Ren revised the manuscript. All authors read and approved the final manuscript.

\section{Acknowledgements}

Not applicable

\section{References}

1. Hak DJ, Mauffrey C, Hake M, Hammerberg EM, Stahel PF. Ipsilateral femoral neck and shaft fractures: current diagnostic and treatment strategies. Orthopedics. 2015;38(4):247-251.

2. Palvanen M, Kannus P, Niemi S, Parkkari J. Update in the epidemiology of proximal humeral fractures. Clin Orthop Relat Res. 2006;442:87-92.

3. Li Y, Zhao L, Zhu L, Li J, Chen A. Internal fixation versus nonoperative treatment for displaced 3-part or 4-part proximal humeral fractures in elderly patients: a Meta-analysis of randomized controlled trials. PLoS One. 2013;8(9):e75464.

4. Ge W, Sun Q, Li G, Lu G, Cai M, Li S. Efficacy comparison of intramedullary nails, locking plates and conservative treatment for displaced proximal humeral fractures in the elderly. ClinInterv Aging. 2017; 12:2047-2054.

5. Pinkas D, Wanich TS, DePalma AA, Gruson KI. Management of malunion of the proximal humerus. J Am AcadOrthopSurg. 2014;22(8):491-502.

6. Handoll HH, Ollivere BJ, Rollins KE. Interventions for treating proximal humeral fractures in adults. Cochrane Database Syst Rev. 2012;12:D434.

7. Mao Z, Zhang L, Zhang L, Zeng X, Chen S, Liu D, Zhou Z, Tang P. Operative versus nonoperative treatment in complex proximal humeral fractures. Orthopedics. 2014;37(5):e410-e419.

8. Ockert B, Siebenbürger G, Kettler M, Braunstein V, Mutschler W. Long-term functional outcomes (median 10 years) after locked plating for displaced fractures of the proximal humerus. J Shoulder Elbow Surg. 2014;23(8):1223-1231.

9. Konrad G, Audigé L, Lambert S, Hertel R, Südkamp NP. Similar outcomes for nail versus plate fixation of three-part proximal humeral fractures. Clin Orthop Relat Res. 2012;470(2):602-609.

10. Thanasas $C$, Kontakis G, Angoules A, Limb D, Giannoudis P. Treatment of proximal humerus fractures with locking plates: A systematic review. J Shoulder Elbow Surg. 2009;18(6):837-844.

11. Sproul RC, lyengar JJ, Devcic Z, Feeley BT. A systematic review of locking plate fixation of proximal humerus fractures. Injury. 2011;42(4):408-413.

12. Tepass A, Rolauffs B, Weise K, Bahrs SD, Dietz K, Bahrs C. Complication rates and outcomes stratified by treatment modalities in proximal humeral fractures: a systematic literature review from 1970-2009. Patient Saf Surg. 2013;7(1):34. 
13. Kitson J, Booth G, Day R. A biomechanical comparison of locking plate and locking nail implants used for fractures of the proximal humerus. J Shoulder Elbow Surg. 2007;16(3):362-366.

14. Yoon RS, Dziadosz D, Porter DA, Frank MA, Smith WR, Liporace FA. A comprehensive update on current fixation options for two-part proximal humerus fractures. Injury. 2014;45(3):510-514.

15. Zhu Y, Lu Y, Shen J, Zhang J, Jiang C. Locking intramedullary nails and locking plates in the treatment of two-Part proximal humeral surgical neck fractures. J Bone Joint Surg Am. 2011;93(2):159-168.

16. Noda M, Saegusa Y, Maeda T. Does the location of the entry point affect the reduction of proximal humeral fractures? Acadaveric study. Injury. 2011;42:S35-S38.

17. Helfen T, Siebenbürger G, Mayer M, Böcker W, Ockert B, Haasters F. Operative treatment of 2-part surgical neck fractures of the proximal humerus (AO 11-A3) in the elderly: Cement augmented locking plate Philos ${ }^{\text {TM }}$ vs. proximal humerus nail MultiLoc ${ }^{\circledR}$. BMC Musculoskelet Disord. 2016;17 (1):448.

18. Boileau P, D Ollonne T, Bessière C, Wilson A, Clavert P, Hatzidakis AM, Chelli M. Displaced humeral surgical neck fractures: classification and results of third-generation percutaneous intramedullary nailing. J Shoulder Elbow Surg. 2019;28(2):276-287.

19. Rothstock S, Plecko M, Kloub M, Schiuma D, Windolf M, Gueorguiev B. Biomechanical evaluation of two intramedullary nailing techniques with different locking options in a three-part fracture proximal humerus model. Clin Biomech. 2012;27(7):686-691.

20. Neer CN. Displaced proximal humeral fractures. I. Classification and evaluation. J Bone Joint Surg Am. 1970;52(6):1077-1089

21. Chen W, Zhang T, Wang J, Liu B, Hou Z, Zhang Y. Minimally invasive treatment of displaced femoral shaft fractures with a rapid reductor and intramedullary nail fixation. Int Orthop. 2016;40(1):167-172.

22. Stedtfeld $\mathrm{H}$, Mittlmeier T. Fixation of proximal humeral factures with an intramedullary nail: tipps and tricks. Eur J Trauma Emerg Surg. (2007;33(4):367-374.

23. CRUESS RL. Experience with steroid-induced avascular necrosis of the shoulder and etiologic considerations regarding osteonecrosis of the hip. Clin Orthop Relat Res. 1978;(130):86-93.

24. Cuny C. Proximalhumerus fractures: editorial. Eur J Orthop Surg Traumatol. 2017;27(3):279-284.

25. Neer CN. Displaced proximal humeral fractures. II. Treatment of three-part and four-part displacement. J Bone Joint Surg Am. 1970;52(6):1090-1103

26. Hertel R, Hempfing A, Stiehler M, Leunig M. Predictors of humeral head ischemia after intracapsular fracture of the proximal humerus. J Shoulder Elbow Surg. 2004;13(4):427-433.

27. Osterhoff G, Ossendorf C, Wanner GA, Simmen H, Werner CM. The calcar screw in angular stable plate fixation of proximal humeral fractures-a case study. J Orthop Surg Res. 2011;6(1):50.

28. Cha H, Park K, Oh S, Jeong J. Treatment of comminuted proximal humeral fractures using locking plate with strut allograft. J Shoulder Elbow Surg. 2017;26(5):781-785. 
29. Füchtmeier B, May R, Hente R, Maghsudi M, Völk M, Hammer J, Nerlich M, Prantl L. Proximal humerus fractures: a comparative biomechanical analysis of intra and extramedullary implants. Arch Orthop Trauma Surg. 2007;127 (6):441-447.

30. Hessmann MH, Hansen WS, Krummenauer F, Pol TF, Rommens P. Locked plate fixation and intramedullary nailing for proximal humerus fractures: a biomechanical evaluation. J Trauma. 2005;58(6):1194-1201.

31. Bernard J, Charalambides C, Aderinto J, Mok D. Early failure of intramedullary nailing for proximal humeral fractures. Injury. 2000;31(10):789-792.

32. Gracitelli MEC, Malavolta EA, Assunção JH, Kojima KE, Dos Reis PR, Silva JS, Ferreira Neto AA, Hernandez AJ. Locking intramedullary nails compared with locking plates for two- and three-part proximal humeral surgical neck fractures: a randomized controlled trial. J Shoulder Elbow Surg. 2016;25(5):695-703.

33. Xiang M, Yang G, Zou Y, HU X, Chen H, Deng M, Gong C, Li Y, Dong J. A comparison study of phlios plate and multiloc nail in treatment of proximal humerus fractures. Chin J Orthop. 2017;37(21):13331341. [Article in Chinese]

34. Li M, Wang Y, Zhang Y, Yang M, Zhang P, Jiang B. Intramedullary nail versus locking plate for treatment of proximal humeral fractures: A meta-analysis based on 1384 individuals. J Int Med Res. 2018;46(11):4363-4376.

\section{Figures}




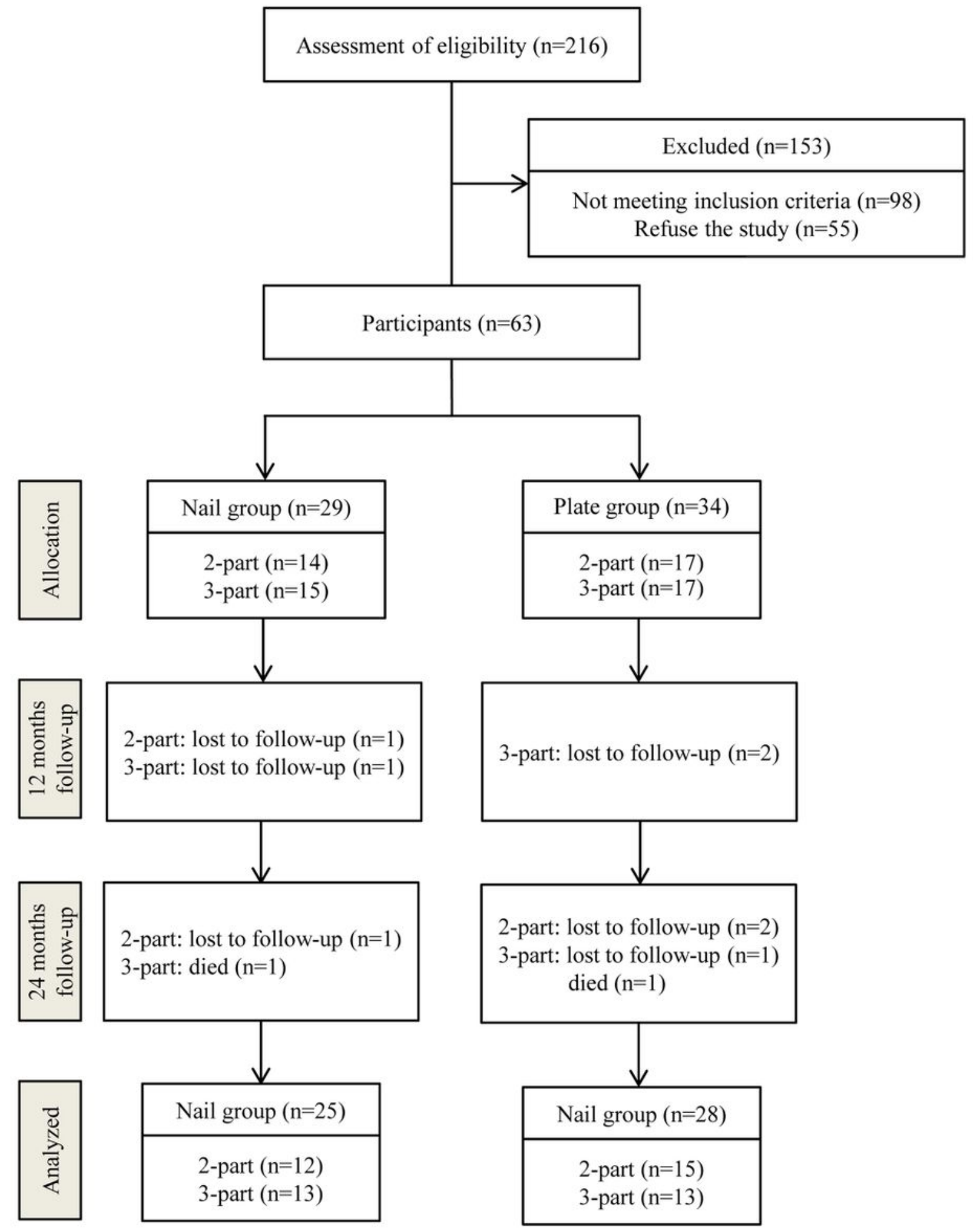

Figure 1

Flow chart for trial enrollment and analysis. 


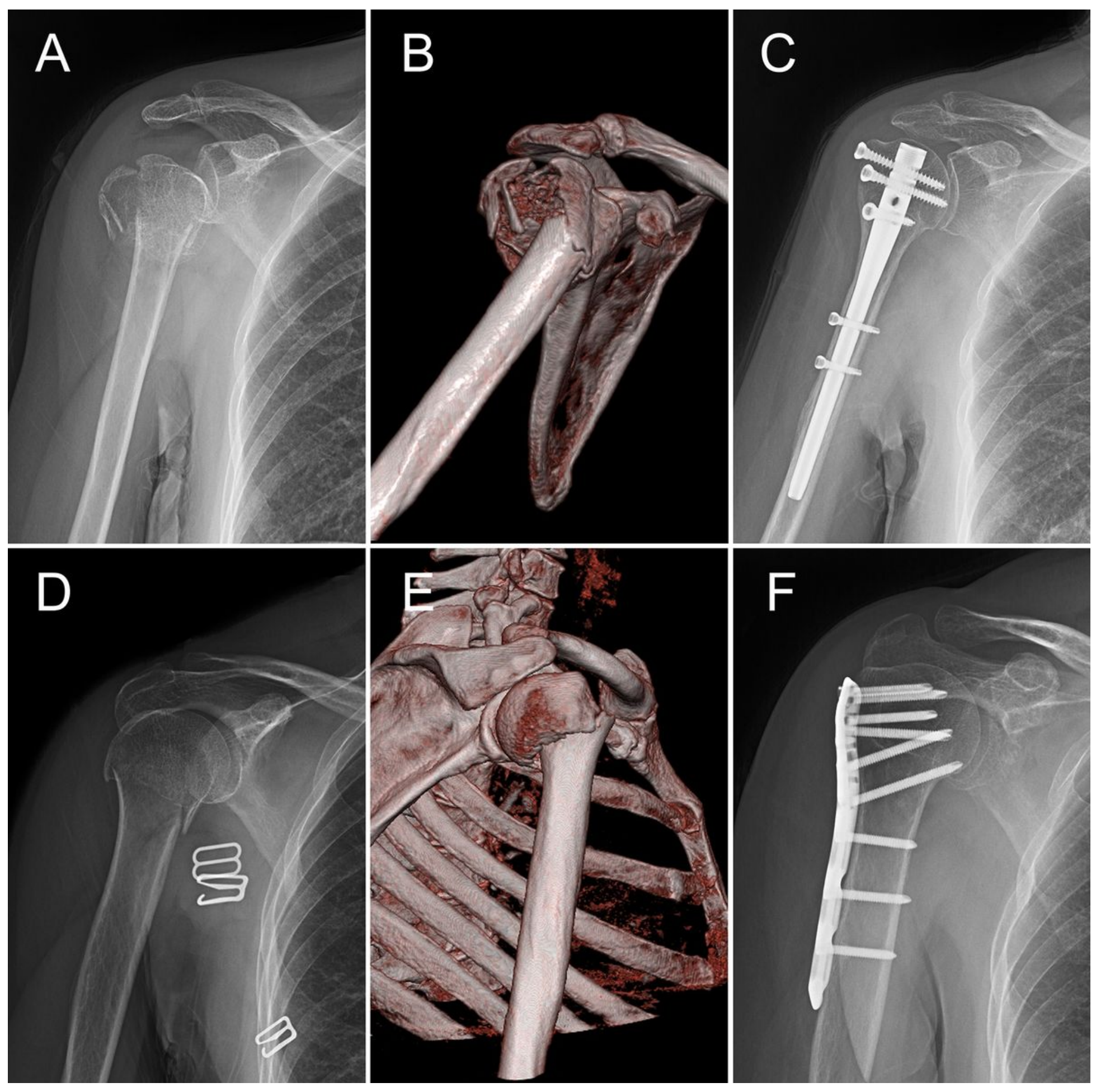

Figure 2

Two typical cases. Three-part proximal humeral surgical neck fracture (female, aged 70 years) treated with locking intramedullary nails $(a, b$ and $c)$. Two-part proximal humeral surgical neck fracture (female, aged 65 years) treated with locking plate ( $d$, e and $f$ ). a and $d$ Preoperative radiograph. $b$ and $e$ Preoperative CT 3D reconstruction. $c$ and f Radiograph at 24 months postoperatively 


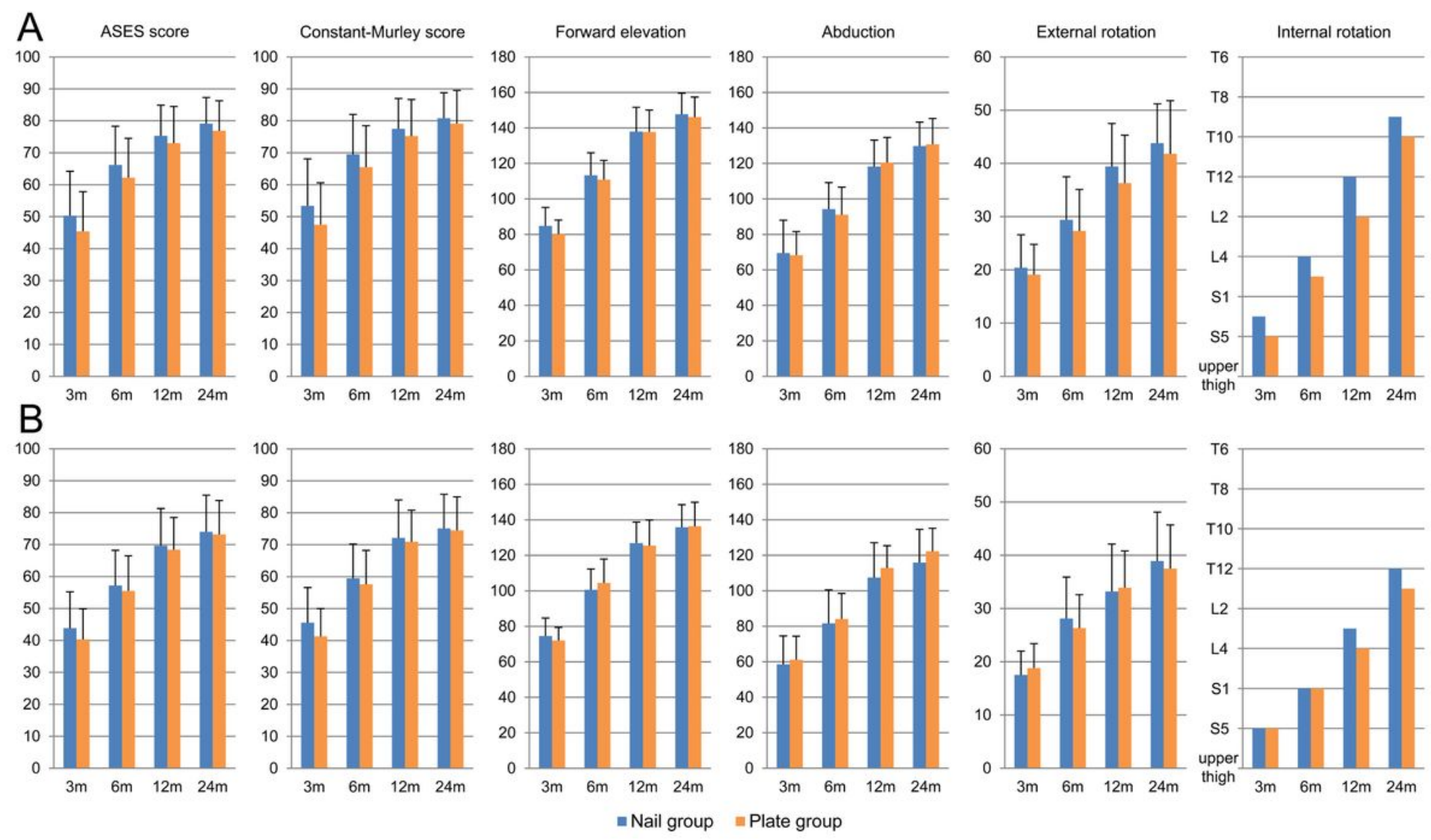

Figure 3

Functional outcomes of locking intramedullary nails and locking plates for 2-part (a) and 3-part (b) proximal humeral surgical neck fractures. Internal rotation is presented as the median, and others are presented as the mean and standard deviation in the figure. ASES: American Shoulder and Elbow Surgeons 

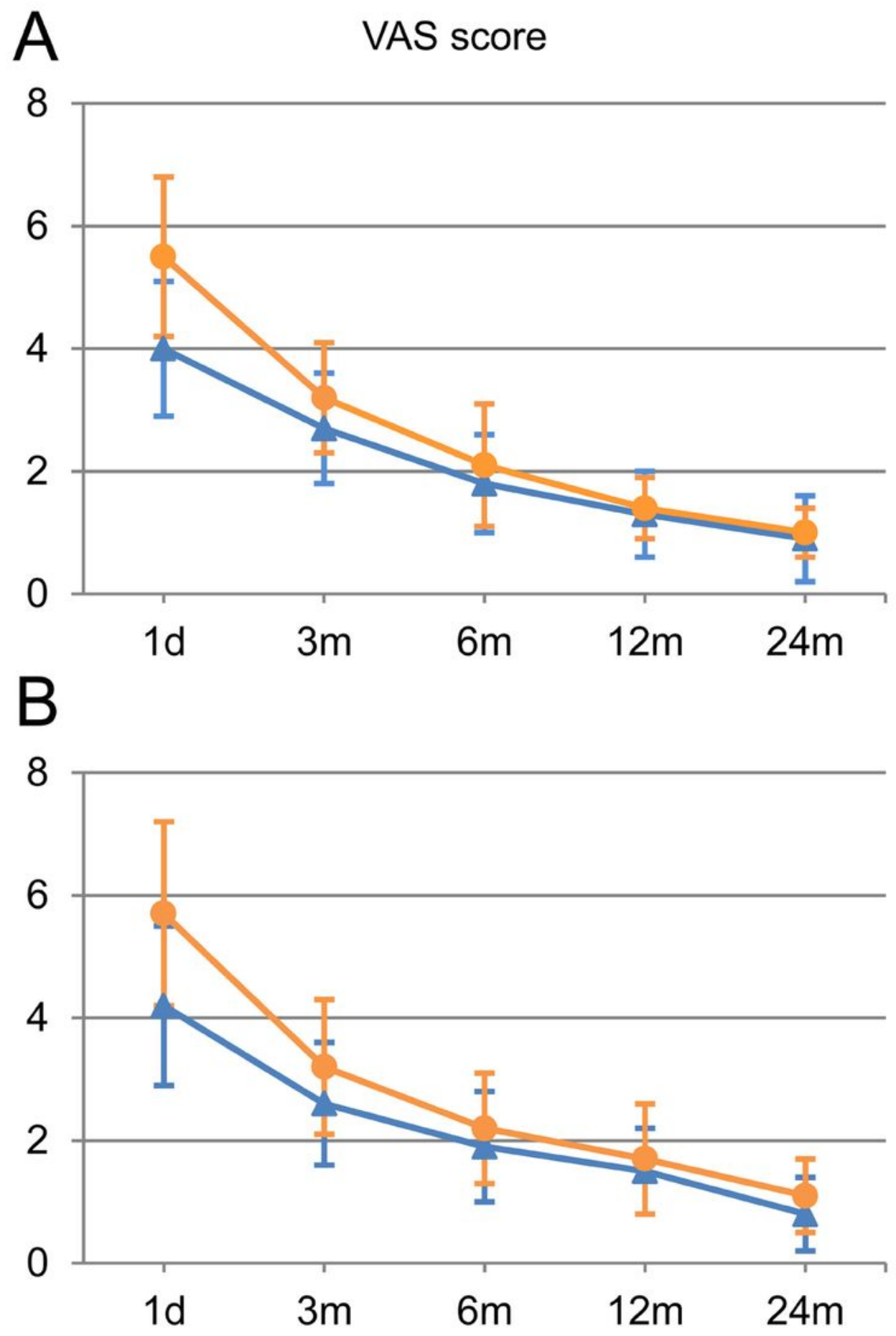

$\neg$ Nail group $\rightarrow$ Plate group

\section{Figure 4}

VAS scores of locking intramedullary nails and locking plates for 2-part (a) and 3-part (b) proximal humeral surgical neck fractures. VAS scores are presented as the mean and standard deviation in the figure. VAS: visual analog scale

\section{Supplementary Files}


This is a list of supplementary files associated with this preprint. Click to download.

- Additionalfile1Rehabilitationprotocol.docx 